\title{
El análisis de la Cohesión, Vinculación e Integración sociales en las encuestas EgoNet ${ }^{1}$
}

\author{
Carlos Lozares), Pedro López Roldán, Joan Miquel Verd, Joel Marti, Mireia \\ Bolíbar, Irene Cruz, - QUIT, Departamento de Sociología² (UAB). \\ Jose Luis Molina, - Egolab, Departamento de Antropología social y cultural \\ $(\mathrm{UAB})^{3}$
}

\section{Resumen}

El objetivo de este artículo consiste en mostrar algunas de las posibilidades de análisis que ofrecen las redes Ego-centradas en lo que se refiere a la Cohesión, Vinculación e Integración social. El artículo indaga en ellas haciendo una propuesta de operativización de dichos conceptos y de análisis a partir de un caso de aplicación. Los datos empleados en los ejemplos ilustrativos de los conceptos provienen de una encuesta de redes Ego-centradas realizada en Catalunya.

Palabras clave: Cohesión social - Integración social - Vinculación social Indicadores - Redes sociales - Redes ego-net - Bonding - Linking - Bridging.

\begin{abstract}
The objective of these papers consists to showing some possibilities of analysis Ego-net about social Cohesion, Linking and Integration. A proposal is done in order to analyze these concepts. The data used in the illustrative examples of the concepts come from a survey of Ego-centered networks in Catalonia.
\end{abstract}

Key words: Social cohesion - social Integration - social Linking - social Networks - Networks ego-net - Bonding - Linking - Bridging.

\footnotetext{
${ }^{1}$ Este artículo es parte de la investigación cuya referencia es CSO2008-01470, subvencionada por el Ministerio de Educación y Ciencia en el marco del VI Plan Nacional de Investigación Científica, Desarrollo e Innovación Tecnológica 2008-2011. Los autores de este artículo pertenecen a dicho proyecto

2 Enviar correspondencia a Carlos.lozares@uab.cat, Centre d'Estudis Sociològics sobre la Vida Quotidiana i el Treball (QUIT), Institut d'Estudis del Treball, (IET) Departament de Sociologia. Universitat Autònoma de Barcelona. 08193. Bellaterra. Cerdanyola del Vallès (Barcelona). Tel: 93.581.2405 / 93.581.1676. Fax: 93.581.2827.

3 Egolab-Grafo (www.egolab.cat).
} 


\section{Introducción}

El artículo muestra algunas de las posibilidades de análisis que ofrecen las redes Ego-centradas sobe la Cohesión, Vinculación e Integración social. A partir de una aproximación reticular a dichos conceptos trata de operacionalizarlos y de ejemplificarlos con una aplicación.

El artículo desarrolla, en primer lugar, los conceptos de Cohesión social, Vinculación social e Integración social en una perspectiva reticular; en segundo lugar, se examinan las diferentes posibilidades de análisis que ofrecen las redes personales con respecto a dichos conceptos; en tercer lugar, se da cuenta de la naturaleza de una encuesta de redes-personales $y$, en cuarto lugar, se operativizan los conceptos precedentes y se llevan a cabo algunos análisis como aplicación de los indicadores propuestos.

Las propuestas de análisis que se hacen, primero, son sólo de carácter bivariado dejando de lado por ahora otras posibilidades y segundo, se refieren sólo a los vínculos que se establecen entre las categorías de los Egos con las correspondientes categorías de los Alteri; es decir, no se proponen análisis de las redes socio-métricas de los Egos. Las propuestas son de carácter abierto ya que se emplean diversos indicadores para un mismo concepto expresando sus limitaciones y su marco de interpretación.

\section{Los conceptos de Cohesión social, Vinculación social e Integración social}

Las definiciones que proponemos de estos conceptos se inscriben en una visión relacional de los fenómenos sociales. En este artículo se ofrece una definición e interpretación sucinta de cada una de ellas ${ }^{4}$.

\section{La Cohesión social}

Tal y como se señala en Lozares, Verd, López-Roldán, Martí, Molina, Bolibar, Cruz, (2011), la Cohesión social es un concepto diversamente connotado desde el punto de vista de su contenido. Genéricamente se refiere a la confianza, identidad, valores comunes, solidaridad, inserción social, redes, etcétera, en un colectivo o

\footnotetext{
4 Para una ampliación de dichos conceptos y perspectiva, ver Lozares, Verd, López-Roldán, Martí, Molina, Bolibar y Cruz, 2011; Granovetter, 1973, 1974; Burt, 1992; Knoke 1999; Brehm y Rahn, 1997; Loury, 1992; Woolcock, 2003; Borgatti, Jones y Everett, 1998; Adler y alt., 2000, 2002; Lin, 1999; 2001; Adler y Kwon, 2000, 2002; Narayan,1999; Vranken, 2001; Woolcock y Narayan, 2000; Szreter y Woolcock, 2004; Cheong, Edwards, Goulbourne y Solomos, 2007; Lozares, 1996, 2006; Verd, Lozares, Martí y López, 2000.
} 
REDES- Revista hispana para el análisis de redes sociales

Vol.20,\#4, Junio 2011

http://revista-redes.rediris.es

sociedad. Varios de estos conceptos coinciden con la definición que se da del Capital Social. Independientemente del contenido, identificamos también la Cohesión social de un colectivo, grupo o población, desde un punto de vista más formal, por las relaciones internas, intra o dentro de los miembros del colectivo. Las relaciones son pues una clave para operacionalizar la Cohesión social y para dar cuenta de la forma en que el Capital social se distribuye en un colectivo (Lozares, Verd, López-Roldán, Martí, Molina, Bolibar y Cruz, 2011). Por tanto en la Cohesión social se conjugan un contenido y una forma. Como se acaba de afirmar, los contenidos de las relaciones, y por tanto de la Cohesión social, pueden ser diversos, por ejemplo, cognitivos como representaciones mutuas y/o de inteligencia emocional que es el terreno de la confianza, información; fácticos de apoyo y solidaridad; económicos; proyecto común como en las comunidades de prácticas, etc. Pero dado su componente formal se puede hablar de una Cohesión social mayor o menor, dependiendo, entre otros indicadores, pe. de la densidad de las relaciones internas de un colectivo. Así pues, las relaciones que definen la Cohesión son las internas o dentro del colectivo, que se denominan lazos Bonding ${ }^{5}$.

\section{La Vinculación social}

La Vinculación social, como sucede con la Cohesión, se compone de una forma relacional y de un contenido que puede ser equivalente al de la Cohesión social y que se corresponde con el contenido de la relación. En la Vinculación social las relaciones son entre diferentes colectivos, por tanto son relaciones inter o entre colectivos previamente definidos por sus entidades. Por tanto, dichos colectivos han de estar previamente definidos de manera intensiva o extensiva. La orientación de las relaciones es hacia fuera; en las Cohesión lo son hacia adentro. Pero en ambas son horizontales; es decir, los vínculos se hacen entre las entidades de los colectivos de una misma envergadura social: entre individuos de dos colectivos, incluso tomando un solo individuo como un colectivo; entre dos colectivos formados por individuos pe. las relaciones de investigación entre dos departamentos a partir de los vínculos en proyectos de investigación de miembros de ambos departamentos. Estas relaciones de tipo 'bilateral' entre individuos o grupos de colectivos diferentes se denominan en la literatura Bridging. De nuevo, los lazos o relaciones dan la intensidad a la Vinculación social y por consiguiente la

\footnotetext{
${ }^{5}$ La traducción de Bonding podría ser lazo, vínculo, enlace,... expresado además de forma activada. Dada la posible polivalencia y ambigüedad a que puede lar lugar la traducción de los tres términos bonding, bridging y linking, se prefiere guardar aquí dichas la expresiones en inglés dándoles una interpretación formal y como definición la orientación de las relaciones que va apareciendo en cada apartado. Además estos términos comienza a tener una cierta aceptación en la literatura en castellano referida a esta cuestión.
} 
REDES- Revista hispana para el análisis de redes sociales

Vol.20,\#4, Junio 2011

http://revista-redes.rediris.es

operativizan; el contenido es el de la relación. Como en la Cohesión social se ha de delimitar tanto la extensión y frontera de los colectivos a los que se refiere la Vinculación social así como la naturaleza de las entidades correspondientes: individuos, grupos, organizaciones. También los contenidos de la Vinculación social pueden ser diversos. Así pues la Vinculación social es otra forma de distribución del Capital social o una manera de mostrarse su estructura.

\section{La Integración social}

Idénticamente a la Cohesión social, el concepto de Integración social ha sido también objeto de interpretaciones diversas en la literatura desde el punto de vista de su contenido (Lozares, Verd, López-Roldán, Martí, Molina, Bolibar y Cruz, 2011). La componente formal de la Integración social consiste también de las relaciones que se dan entre miembros de dos colectivos. La identidad sustantiva de la Integración social puede corresponder a contenidos como el económico, confianza mutua, apoyo, etcétera. Como sucede en la Cohesión y Vinculación, la Integración social es la conjunción de dos componentes, la forma de relacionarse dos colectivos y como contenido el de sus relaciones. La diferencia con la Cohesión social y con la Vinculación social es entonces una cuestión de orientación relacional. Como en la Vinculación social, las relaciones en la Integración son entre dos colectivos con lo que de nuevo es decisiva la neta definición previa, tanto de los colectivos de los que se predica la Integración como de la naturaleza de sus entidades. La diferencia con la Vinculación consiste en que la naturaleza de las entidades que se integran son diferentes: en la Vinculación las entidades de los colectivos son igualitarias, en la Integración las entidades son de diferente envergadura social; pe. de un individuo como con respecto a todos individuos del colectivo o con los que tienen más poder, dinero, prestigio, etc.; de un departamento en el conjunto de todos los departamentos; de una asociación en todo el entramado asociativo de una ciudad y/o con asociaciones con más 'poder' social; de los miembros de la clase media con el conjunto de las clases sociales de una población o con las que se encuentran en un ranking superior. Se trata pues de relaciones entre, inter o hacia fuera pero de carácter vertical, dada la escala social diferenciada de de individuos o de colectivos. Los lazos linking expresan, en la literatura del CS, las relaciones que los miembros de un colectivo tienen con los de otro u otros colectivos diferentes. Los linking son pues potenciales indicadores adecuados de la Integración social y en este sentido son interpretados. Emplearemos pues la expresión linking para estas relaciones inter, externas y verticales. Se puede hablar de mayor o menor Integración según la intensidad de tales las relaciones. Como se precisará más adelante, se dan diversas formas de 
REDES- Revista hispana para el análisis de redes sociales

Vol.20,\#4, Junio 2011

http://revista-redes.rediris.es

contemplar estas relaciones inter o entre colectivos. La Integración social es pues otra forma de distribución del CS en perspectiva reticular y de expresar su estructura. En este sentido, la forma de la Integración social es también neutral aunque sea aplicable sustantivamente en campos sociales diferentes.

\section{Las diferentes posibilidades de análisis de las encuestas Ego- centradas}

A partir de las definiciones de Cohesión social, Vinculación social e Integración social parece que las redes personales y las socio-métricas pueden ser la base y los mecanismos e indicadores para dar cuenta de dichos conceptos. En efecto, en las redes personales y socio-métricas los conjuntos de unidades o nodos (individuos o entidades sociales) han de estar perfectamente delimitados $y$ definidos; lo mismo podemos decir sobre la naturaleza de dichas unidades tanto en su envergadura social como en su contenido sustantivo, lo que permite conocer el contenido de las Cohesión, Vinculación e Integración social. Por fin, y sobre todo, se han de disponer de una asignación y/o estructura relacional entre las entidades pe. individuos de los que se predican estos conceptos; este es el caso de las redes personales y de las redes socio-métricas. Particularmente las sociométricas contienen una serie de indicadores adecuados para la medición de dichos conceptos, cliques, kores, facciones, equivalencias estructurales u otros indicadores mencionados.

La pregunta que nos hacemos es, ¿se pueden analizar los conceptos de la Cohesión, Vinculación e Integración social por medio de las redes ego-centradas y las socio-métricas? Veamos dos posibilidades. La primera, tiene en cuenta las redes socio-métricas entre los Alteri para cada Ego que. como veremos, admite una bifurcación. Sobre esta propuesta no se hace una aplicación en este artículo. La segunda posibilidad sólo tiene en cuenta las relaciones personales directas de los Egos, o sus categorías, con sus Alteri; las denominamos, dada su exclusiva centralidad en los atributos y la relación del Ego con los Alteri, Cohesión homofílicas y Vinculación e Integración heterofílicas. Esta posibilidad es la que es objeto de aplicación en este artículo, (para la distinción entre Cohesión e Integración sociométricas y Cohesión e Integración homofílicas ver, Lozares y Verd, 2011)

La posibilidad de la Cohesión, Vinculación e Integración socio-métricas.

\section{1) Primera modalidad}

Se trata de la caracterización de los Egos y de sus categorías a partir de la Cohesión social, bonding, Vinculación social, bridging e Integración social, linking, 
REDES- Revista hispana para el análisis de redes sociales

Vol.20,\#4, Junio 2011

http://revista-redes.rediris.es

de las relaciones sociométricas de sus Alteri. Es una manera de estructurar los Egos y sus atributos. Es lo que denominamos Cohesión, Vinculación e Integración socio-métricas.

En la información de las redes personales se da, además de las características de los Egos y sus vínculos con los Alteri una red sociométrica para cada Ego. El contenido de dichas relaciones está definido por el analista en función de los intereses del estudio. Lo habitual es elegir un contenido básico como es el conocimiento y reconocimiento mutuo y su potencial reproducción en el futuro. Éste será el contenido que se darán a los tres conceptos de Cohesión, Vinculación e Integración social en todas las posibilidades de análisis que presentamos. La razón de esta elección es que dicho contenido es condición necesaria para cualquier otro como los de apoyo y sostén, confianza o información.

En el estudio de un solo Ego la Cohesión, Vinculación e Integración sociométricas se referirán a dicho Ego; es un estudio de caso único. El caso único tiene un interés relativo pero puede incrementarse si se hace para todo un colectivo de Egos y sobre todo si se hace como un estudio de comparación de casos entre características de los Egos. Los indicadores para caracterizar los Egos reticularmente o sus colectivos son los que se refieren a los bonding, bidging $y$ linking de la redes socio-métricas correspondientes.

Sentados dichos preámbulos para esta modalidad de análisis, el procedimiento es el siguiente. (i) Se examinan para cada Ego las redes sociométricas entre los Alteri por medio de los indicadores reticulares de bonding, bidging y linking para inferir y caracterizar el grado de Cohesión, Vinculación e Integración sociométricas de la red para atribuirlas a cada Ego; (ii) a partir de las categorías de los Egos, por ejemplo Hombres v. Mujeres o de tipologías construidas ad hoc, se atribuye la Cohesión, Vinculación e Integración sociométricas a dichas categorías. Como se ha anunciado esta modalidad no es objeto de aplicación en este artículo.

\section{1) Segunda modalidad}

Esta modalidad va en el sentido opuesto al precedente: de las estructuras o modelos bonding, bidging y linking que estructuran las redes sociométricas de los Alteri para cada (o todos) Egos se pasa a analizar su asociación o correspondencia con las categorías de los Egos. El procedimiento es el siguiente: (i) se parte las redes socio-métricas entre los Alteri para uno, un colectivo o de todos los Egos; (ii) se analizan dichas redes con indicadores reticulares de bonding, bidging $y$ linking y se concluye sobre el grado de Cohesión social, Vinculación social e 
REDES- Revista hispana para el análisis de redes sociales

Vol.20,\#4, Junio 2011

http://revista-redes.rediris.es

Integración social para dicha(s) característica(s); por último (iii) se halla el grado de correspondencia, en el caso, con características de los Egos. Esta modalidad tampoco se presenta en este artículo.

La posibilidad atributiva o la Cohesión, Vinculación e Integración homofílica

Se trata de la asociación de las características o colectivos de los Egos con las de sus Alteri a través de los vínculos de conocimiento-relación mutuos, sin entrar en las redes socio-métricas de los Alteri. Para ello, primero, se han de dar un número suficiente de encuestas Ego-centradas para ir más allá del caso único de estudiar un solo Ego; sobre todo si los resultados han de tener una mínima representatividad. En segundo lugar, se supone, como es propio a las redes Egocentradas, que tanto los Egos como sus Alteri estén caracterizados por una serie de atributos, grupos de pertenencia o características idénticos para hacer la asociación. Por ejemplo, que si entre las variables del Ego está la de Categoría socio profesional esta variable ha de estar también para los Alteri y con sus mismos valores, si deseamos calcular su Cohesión, Vinculación y/o Integración social. El método del proceso propuesto consiste en los pasos siguientes. (i) Se asocian por análisis bivariado de tablas de contingencias las dos variables equivalentes de Egos y de Alteri. Este cruce supone un vínculo entre Egos y Alteri como son las relaciones de mutuo conocimiento; (ii) los porcentajes, residuos estandarizados o ajustados y las medidas de los índices globales de asociación pueden dar cuenta del nivel del Cohesión, Vinculación e Integración social del colectivo de Egos de una característica dada con el equivalente del Alter. Se supone que estos procesos pueden llevarse a cabo para variables tipológicas construidas a partir de las iniciales y no sólo por análisis bivariados sino también para multivariados como pe. de correspondencias.

Hablamos de Cohesión, Vinculación e Integración de carácter homofílico por la existencia de relaciones previas entre Ego y Alteri como es el conocimiento mutuo. Los Egos y sus Alteri están pues relacionados, no son entidades distribuidas aleatoriamente; los Alteri son 'atributos relacionales' de los Egos. El dato primero es pues la relación sobre la que se cruzan categorías en el proceso de asociación optado. Lo que se examina es si las relaciones de un Ego con sus Alteri son más probables entre determinadas categorías. En este sentido, se supera y va más allá y por tanto difiere del tratamiento que se hace en la tradición de los estudio de la Homofilia, sin que corresponda exactamente a los procedimientos de Cohesión, Vinculación e Integración a partir de redes socio-métricas. Si añadimos el concepto de homofilia es porque se trata de relaciones entre características de 
REDES- Revista hispana para el análisis de redes sociales

Vol.20,\#4, Junio 2011

http://revista-redes.rediris.es

Egos y de los Alteri sin entrar en las relaciones o matrices socio-métricas de los Alteri.

\section{La encuesta Ego-net objeto de la aplicación presentada}

\subsection{El contenido y objetivo genérico de la investigación y encuesta}

Los estudios de redes Ego-centradas o personales se pueden llevar a cabo, bien para un solo Ego, bien para varios de un mismo colectivo como análisis de caso único, pero también de diversos colectivos para estudios comparados, con mayor o menor grado de representatividad. Como es sabido, a los Egos se les pregunta sobre una serie de características o atributos sociales propios, sobre los Alteri de los Egos y sobre las relaciones que mantienen los Alteri a partir de un criterio relacional como pe. el del conocimiento o tratamiento mutuo, pero podría ser otro. Habitualmente, se elige un colectivo determinado de Egos, por ejemplo, de un tipo de inmigración, de una secta o grupo religioso, de una etnia, etcétera, sin comparación con otros grupos o colectivos; es menos frecuente comparar colectivos. Como se detalla más adelante, el ejemplo de aplicación es sobre 6 colectivos referidos poblaciones diferenciadas en la sociedad catalana que además representan situaciones de inserción diferente en Catalunya por representar oleadas de originarios e inmigrantes; lo que permite una gran riqueza informativa y comparativa.

En las encuestas habituales de redes Ego-centradas, las preguntas que se hacen a los Egos sobre sí mismos como las que se los hacen sobre sus Alteri no acostumbran a ser numerosas. Por el contrario, en nuestro caso son numerosas y muchas de ellas coincidentes con las de los Egos. De nuevo esta amplitud posibilita plantear la comparación entre muchos colectivos de Egos con los equivalentes de los Alteri en vistas a calcular la Cohesión, Vinculación e Integración social de los colectivos, es decir de cariz homofílico (ver Anexos 1 y 3 sobre las variables de Egos y Alteri).

El contenido de la relación, suministrada por el Ego sobre sus Alteri, y también sobre la relación entre sus Alteri es la de conocimiento y trato recíproco, (ver Anexo 2). Esto quiere decir que los contenidos dados a la Cohesión, Integración y Vinculación tanto homofílicas como socio-métricas no van más allá ni más acá de tal significado. Por tanto, se han de eliminar de la interpretación de los análisis otras proyecciones semánticas dadas a la Cohesión, Integración y Vinculación social. por ejemplo las connotaciones normalmente asociadas a dichos conceptos como valores comunes o compartidos, identidad propia, apoyo mutuo, etcétera, a 
REDES- Revista hispana para el análisis de redes sociales

Vol.20,\#4, Junio 2011

http://revista-redes.rediris.es

no ser que en la encuesta se pida una relación determinada. Como afirmábamos el conocimiento y trato recíproco es la condición previa para cualquier otro contenido relacional. Pero no hay óbice para que se hagan, como se hacen, preguntas que se refieren a otros contenidos más específicos que suponen o tienen como consecuencia el conocimiento mutuo (ver Anexo 3).

El objetivo de la investigación y por tanto de la encuesta y su análisis, consiste primero, en un análisis comparado de casos entre categorías de Egos y las correspondientes de sus Alteri en vistas a concluir sobre la Cohesión, Integración y Vinculación homofílicas y, segundo, en elaborar modelos de comportamientos a partir de las redes socio-métricas de los Alteri en vistas obtener leyes generales o examinar comportamientos diferenciados de los Egos relacionales para concluir sobre Cohesión, Integración y Vinculación socio-métricas. Sólo el primer objetivo es el que se persigue en este artículo que además se restringe a proponer, con un ejemplo de aplicación, algunos indicadores de medición de la Cohesión, Integración y Vinculación homofílica. Además la ejemplificación sólo se lleva a cabo sobre los colectivos de base tomados como criterio de estratificación de la encuesta, es decir, el origen vinculado a la edad y a la tipología de ciudad. Se especifican en el siguiente apartado. Sin embargo, existe suficiente información en la encuesta como para extender dicho análisis a numerosos otros campos sociales: CSP, género, lengua, o al cruce de dichos atributos, como también a otros contenidos relacionales como la proximidad de amistad o el nivel de confianza la pertenencia a las mismas asociaciones, empresa, soportes o ayudadas específicas, etcétera

\subsection{Los colectivos objeto de aplicación: origen, edad y ciudades}

La elección de los colectivos se hace a partir de tres tipos de población de Catalunya que se corresponden con dos oleadas migratorias y con la población autóctona, esto es:

- la residente en Cataluña de padres nacidos en Catalunya,

- la proveniente de otros territorios de España de los años 1950 y 60 además, genéricamente, de la generación de sus hijos

- la inmigración reciente de las que sólo se han elegido los de origen marroquí y ecuatoriano.

Abarca por tanto toda la población salvo la de colectivos de nueva inmigración que no sean marroquíes y ecuatorianos. Estos colectivos, configuran una variable básica de estratificación y han sido elegidos por diversas razones: (i) Representan 
tres orígenes y estancias temporales en Catalunya con lo que significa no sólo de idiosincrasia de origen sino también en las consecuencias que la estancia más o menos prolongada en Catalunya tiene con respecto a la Cohesión, Integración y Vinculación homofílica junto a contenidos como conciencia de pertenencia, identidad, participación, etc. (ii) Las características de dichos colectivos acarrean o conllevan otras diferencias sociales en estatus y categoría social, mercado laboral, niveles de estudios, amén de otras características como hábitos, modos de vida, idioma, costumbres, cultura, etc. (iii) Dichos colectivos constituyen el criterio básico de la estratificación necesaria en la elaboración de la muestra. (iv) El tratamiento de temáticas tales como la Cohesión, Vinculación e Integración social acostumbra a centrarse casi exclusivamente sobre la inmigración sin compararla con la población de otros orígenes o a veces sólo entre colectivos de inmigrantes. Ello puede hacer suponer, primero, que otros sectores de la población, no inmigrante o autóctona ya están cohesionados, integrados, etc. tomándolo de partida como centro de referencia y/o estimando que sólo incumbe a la inmigración. Nuestro enfoque es diferente. El centro de gravedad u origen de nuestras coordenadas en cuestiones de Cohesión, Vinculación e Integración social no es la población de origen o la inmigrante, sino que es el conjunto de las relaciones entre colectivos de toda la población de un territorio en el que habitan y conviven ciudadanos individuales y colectivos. La definición de Cohesión, Vinculación e Integración social es completamente relacional por lo que ningún colectivo tiene la prioridad de ser el centro de referencia modélica o patente previa de dichos conceptos.

Los tres tipos de población de partida se desdoblan: los dos grupos de catalanes por un criterio de edad y de la antigua inmigración en dos tipos, lo que conduce a los seis colectivos definitivos. La división por edad en los dos colectivos de catalanes, los de origen y los provenientes de la inmigración de los 50 y 60, corresponde a dos periodos de cambio y desarrollo importantes desde el punto de vista cultural, político y educativo, esto es, a dos generaciones diferentes. Los cuatro colectivos que surgen de dicho desdoblamiento son los siguientes:

- Catalanes nacidos en Catalunya, de padres catalanes, mayores de 55 años: $\mathrm{NC}+55 \mathrm{pNC}$

- Catalanes nacidos en Catalunya, de padres catalanes, entre 25 y 55 años: NC 25-55pNC

- Catalanes nacidos en el resto de España mayores de 55 años: NE + 55 
REDES- Revista hispana para el análisis de redes sociales

Vol.20,\#4, Junio 2011

http://revista-redes.rediris.es

- Catalanes, nacidos en Catalunya, de padres nacidos en el resto de España, entre 25 y 55 años: NC 25-55pNE

En cuanto a la inmigración reciente, se han elegido dos colectivos, el de los marroquíes y el de los ecuatorianos, por representar dos inmigraciones, no sólo muy diferentes entre sí, sino también por su aproximación a la población autóctona. Estos dos colectivos no se han doblado por la edad al suponer genéricamente que se trata de una población joven o al menos menor de 55 . Por ello se eligen sólo entre 18 y 55 años. Por tanto,

- Origen en Ecuador menores de 55

- Origen en Marruecos menores de 55.

Además del origen y la edad, que conllevan implícitamente otras muchas diferencias, se han elegido sólo tres ciudades que por su desarrollo metropolitano, industrial y urbanístico en estas décadas, son cotejables con otras muchas ciudades de Cataluña con similares características. Estas ciudades son Barcelona como metrópoli central, Sant Feliu como prototipo de cuidad metropolitana, con grandes cambios industriales y urbanísticos en las últimas décadas y por fin Balaguer, ejemplo de ciudad capital de comarca, con una cierta implantación agrícola, administrativa e industrial, aunque bastante menor, y unas formas de vida en las que aún puede ser posible conocerse mutuamente una buena parte de la población.

Para la elección de dichos criterios, Origen asociado a Edad e Inmigración, nos hemos guiado por la muestra realizada en Catalunya para la Enquesta Metropolitana $2005^{6}$. Se llevó a cabo con los datos del censo del 2001, eligiendo como unidades las secciones censales de Catalunya y 82 variables del censo. La muestra fue estratificada basándose en datos censales de tal forma que en lugar de elegir consabidos dos o tres variables como criterios de estratificación se eligieron dimensiones factoriales sobre las 82 variables que representa el $69 \%$ de la variabilidad de la población. Los factores que surgen de dicho cálculo son los siguientes, según el orden del peso en su varianza explicada.

\footnotetext{
${ }^{6}$ Lopez Roldán P., Lozares C., (2008a) y Lopez Roldán P., Lozares C., (2008b).
} 
REDES- Revista hispana para el análisis de redes sociales

Vol.20,\#4, Junio 2011

http://revista-redes.rediris.es

- Factor 1: Categoría socio-profesional.

- Factor 2: Origen geográfico: nacidos en Catalunya versus antigua inmigración.

- Factor 3: El ciclo vital.

- Factor 4: Lo rural versus la gran ciudad (lo urbano).

- Factor 5: La nueva inmigración versus el resto de la población.

- Factor 6: La actividad laboral.

- Factor 7: La movilidad territorial.

El simple recorrido por dichos factores nos muestra que los criterios elegidos como base de nuestro 'muestreo estratificado' son razonables. El factor 2, por ejemplo, tiene en cuenta el origen autóctono versus antigua inmigración; el factor 3 reproduce de alguna manera la edad y la idea de generación y el factor 5 establece la diferencia entre la nueva inmigración del resto de la población. Los tres expresan muy directamente criterios similares a los que constituyen nuestros colectivos y estratificación establecida. Por otro lado, el factor 1 y el 5 guardan un claro grado de correlación con los orígenes de nuestra muestra. Los factores 4 y 7 son de alguna manera tenidos en cuenta con el criterio de tipo de ciudad que complementa los colectivos de origen. Los clusters que surgían de dicho cálculo para establecer los estratos de la muestra tienen un gran parangón con los criterios del análisis factorial. También en cada colectivo y ciudad se han distribuido proporcionalmente las encuestas entre hombres y mujeres.

\subsection{La muestra de la encuesta egocentrada}

Se trata de una muestra para la aplicación de la lógica de las redes Egocentradas. La unidad de muestra es el Ego y derivadamente y a partir de los Egos sus Alteri, que son a manera de atributos de los Egos. La elección de los Egos no ha seguido, en su selección, ni el criterio nominal preestablecido de un conjunto de individuos encuestando a todos los Egos del listado, ni el de la bola de nieve o criterio realista que condiciona la elección de los sucesivos Egos a los Alteri que van nominando los sucesivos Egos como nuevos encuestados hasta lograr la saturación. El criterio elegido ha sido aleatorio y además con diversos métodos de trabajo de campo aplicados en cada una de las ciudades en que se ha realizado: puerta a puerta, contactando asociaciones, anuncios en grupos de facebook, aleatoriedad en la calle, bares, anuncios, contactos mediante conocidos, etcétera. El número de encuestas es importante, $450+(36)$, con un error calculable aunque no suficiente como para asumir errores aceptables en los estándares habituales para el conjunto de las tres ciudades elegidas ni para cada una de ellas. 
El muestreo ha sido por cuotas o estratos, lo que no asegura la generalización de los resultados para cualquiera variable sino para las que siguen la lógica de los estratos ya señalados. De todas maneras los cálculos realizados para otras variables importantes como género, categoría socio-profesional, ocupación o estudios siguen los valores de otras encuestas para toda Catalunya. El muestreo ha sido también polietápico, primero tres ciudades, como se ha indicado, muy diferentes entre sí pero un tanto 'representativas' de tres tipos de ciudades de Catalunya y luego individuos o Egos en ellas elegidos aleatoriamente.

Dicho esto, elegido un Ego que mantiene un número o proporción de relaciones con Alteri de un determinado atributo y que dicha proporción adquiere un valor promedio para todos los Egos en la característica dada de la muestra, este valor es inferible, con el error debido, para los Egos de la población concernida, tengan o no tenga relación entre sí los Egos de una determinada característica.

Se trata pues de una muestra aleatoria, estratificada por cuotas y bietápica pero con un número suficiente como para alcanzar un cierto error. El paso a la representatividad hubiera supuesto la ampliación de las encuestas a aproximadamente otros 650 Egos para llegar a un error del 3\% asumible y la extensión a algunas otras ciudades. De esta muestra, si bien no se puede hablar de la extensión representativa a Catalunya ni tan siquiera a las ciudades elegidas, sí que es posible que cada uno de los colectivos elegidos puede tener, como se afirmaba antes, una base suficiente como para que sea representativo de la población de sus mismas características dada la especificidad y el carácter homogéneo en muchas de sus características sociales que tienen dichos colectivos; es decir, ser la base de estudios de cada colectivo y de su comparación.

\section{La medición y análisis de la Cohesión, Vinculación e Integración social de carácter homofílico}

Los indicadores propuestos se corresponden con los de las tablas de contingencia, en el caso, solamente bivariadas. No se excluyen, para análisis posteriores, otros tipos de indicadores basados en otros métodos que los bivariados de contingencias, como multivariados $u$ otros procedimientos dentro de las posibilidades cuantitativas de redes sociométricas; pero lo que se propone es el punto de partida. Por el momento la intención de este artículo consiste en extraer todas las posibilidades que ofrecen las tablas de contingencia con las evidentes limitaciones o desventajas de su carácter bivariado. 


\subsection{La tabla de contingencias del cruce de Egos y Alteri}

Los colectivos Egos se sitúan en las columnas y su identificación se sitúan en la la primera fila; los colectivos Alteri aparecen en filas para el conjunto de cada Ego y su identidad en la primera columna, (Tabla 1). La tabla leída en columnas representa el número, los porcentajes y los residuos ajustados del conjunto de los colectivos de Alteri para cada uno los colectivos de Egos señalados en la primera fila. El total en cada columna es el 100\%. Los porcentajes leídos en fila representan, la distribución del colectivo Alteri correspondiente a dicha fila el porcentaje de la presencia de de dichos Alteri en los diferentes colectivos de Egos. Por ello la suma en fila de dichos porcentajes no suman 100. El porcentaje final que aparece en cada línea horizontal representa el porcentaje total, sobre 100, del colectivo Alteri de cada fila. La última columna suma 100 pues es la suma de todos los colectivos Alteri. En cada casilla, además de los porcentajes descritos, aparece el número absoluto de Alteri y los residuos ajustados.

\begin{tabular}{|c|c|c|c|c|c|c|c|c|}
\hline \multirow[b]{2}{*}{ rigen Alteri } & & \multicolumn{6}{|c|}{ Origen Egos } & \multirow{2}{*}{ Total } \\
\hline & & \multirow{3}{*}{$\begin{array}{c}1 \mathrm{NC}+5 \\
5 \mathrm{pNC} \\
1696 \\
77,4 \%\end{array}$} & \multirow{2}{*}{$\begin{array}{c}2 \mathrm{NC25-} \\
55 \mathrm{pNC} \\
1610\end{array}$} & \multirow{2}{*}{$\begin{array}{c}\text { 3NC25- } \\
55 \mathrm{pNE} \\
875\end{array}$} & \multirow{2}{*}{$\begin{array}{r}4 \mathrm{NE}+55 \\
548\end{array}$} & \multirow{2}{*}{$\begin{array}{r}\text { Ecuador } \\
270\end{array}$} & \multirow{2}{*}{$\begin{array}{r}\text { Marruecos } \\
227\end{array}$} & \\
\hline $1 \mathrm{y} 2 \mathrm{NC}$ & Count & & & & & & & 5226 \\
\hline \multirow{2}{*}{ pNC } & & & $70,6 \%$ & $39,4 \%$ & $28,1 \%$ & $12,5 \%$ & $10,4 \%$ & $40,2 \%$ \\
\hline & Adj.Res & 38,9 & 32,6 &,- 9 & $-11,8$ & $-28,8$ & $-31,3$ & \\
\hline \multirow{3}{*}{$\begin{array}{l}\text { 3PnE25 } \\
-55\end{array}$} & Count & 201 & 381 & 743 & 418 & 102 & 102 & 1947 \\
\hline & & $9,2 \%$ & $16,7 \%$ & $33,5 \%$ & $21,4 \%$ & $4,7 \%$ & $4,7 \%$ & $15,0 \%$ \\
\hline & Adj.Res & $-8,4$ & 2,5 & 26,8 & 8,7 & $-14,6$ & $-14,9$ & \\
\hline \multirow{3}{*}{$\begin{array}{l}4 \mathrm{NE}+ \\
55\end{array}$} & Count & 257 & 181 & 500 & 936 & 47 & 111 & 2032 \\
\hline & & $11,7 \%$ & $7,9 \%$ & $22,5 \%$ & $48,0 \%$ & $2,2 \%$ & $5,1 \%$ & $15,6 \%$ \\
\hline & Adj.Res & $-5,5$ & $-11,2$ & 9,8 & 42,7 & $-18,9$ & $-14,9$ & \\
\hline \multirow[t]{3}{*}{ Ec } & Count & 1 & 2 & 4 & 4 & 1290 & 19 & 1320 \\
\hline & $\%$ &, $0 \%$ &, $1 \%$ &, $2 \%$ &, $2 \%$ & $59,7 \%$ &, $9 \%$ & $10,2 \%$ \\
\hline & Adj.Res & $-17,2$ & $-17,5$ & $-17,1$ & $-15,8$ & 83,5 & $-15,8$ & \\
\hline \multirow[t]{3}{*}{ Marr } & Count & 1 & 9 & 3 & 3 & 30 & 1602 & 1648 \\
\hline & &, $0 \%$ &, $4 \%$ &, $1 \%$ &, $2 \%$ & $1,4 \%$ & $73,2 \%$ & $12,7 \%$ \\
\hline & Adj.Res & $-19,5$ & $-19,4$ & $-19,5$ & $-18,0$ & $-17,3$ & 93,2 & \\
\hline \multirow[t]{2}{*}{ Otros } & Count & 34 & 97 & 95 & 41 & 421 & 129 & 817 \\
\hline & $\%$ & $1,6 \%$ & $4,3 \%$ & $4,3, \%$ & $2,1 \%$ & $19,5 \%$ & $5,9 \%$ & $6,3 \%$ \\
\hline \multirow[t]{2}{*}{ Total } & Count & 2190 & 2280 & 2220 & 1950 & 2160 & 2190 & 12990 \\
\hline & $\%$ & $100 \%$ & $100 \%$ & $100 \%$ & $100 \%$ & $100 \%$ & $100 \%$ & $100 \%$ \\
\hline
\end{tabular}

Tabla 1. Colectivos Egos $x$ colectivos Alteri correspondientes.

\subsection{Indicadores de la Cohesión social de naturaleza homofílica}

Veamos diferentes posibilidades para el cálculo de la Cohesión social de diferentes colectivos de Egos. El valor de la Cohesión repercute en los de la Integración y Vinculación pues están relacionados. 
REDES- Revista hispana para el análisis de redes sociales

Vol.20,\#4, Junio 2011

http://revista-redes.rediris.es

(1) Primer tipo de Indicadores de la Cohesión social dado por los porcentajes:

Una primera propuesta es el cálculo de la Cohesión social para cada colectivo de los Egos consiste en el valor del porcentaje que aparecen en las casillas en las que coinciden los colectivos de Egos con los de sus Alteri. Veamos dos posibilidades

Primera posibilidad de (1): el valor relativizado con respecto a 100 en columna (Tabla 2).

El valor de la Cohesión varía del mínimo o nulo, el 0\%, al máximo el 100\%. La variación es lineal y por tanto el porcentaje expresa proporcionalidad entre $0 \%$ y $100 \%$. Se puede establecer escalas o niveles de Cohesión social:

\begin{tabular}{|l|c|c|c|c|c|c|}
\hline & NC+55pNC & $\begin{array}{c}\text { NC25- } \\
55 p N C\end{array}$ & $\begin{array}{c}\text { NC25- } \\
55 p N E\end{array}$ & NE+55 & Ecuador & Marruecos \\
\hline Porcentaje & $77,4 \%$ & $70,6 \%$ & $33,5 \%$ & $48,0 \%$ & $59,7 \%$ & $73,2 \%$ \\
\hline
\end{tabular}

Tabla 2. Primera posibilidad de Indicador de Cohesión.

Los colectivos NC25-55pNC y NC25-55pNE tienen el mayor valor de Cohesión $(77,4 \%$ y $70,6 \%)$, muy por encima del resto de los colectivos Egos, salvo el de los marroquíes, comparando en cada caso con los porcentajes de todos los Alteri en cada colectivo de Egos ${ }^{7}$. Es bastante menor en el caso de NC25-55pNE y de $\mathrm{NE}+55$. Es muy elevada en el caso de los marroquíes y un valor medio en el de los Ecuatorianos. Con todo, en este caso es importante señalar que aparece un $20 \%$ de vínculos que tienen con otros colectivos que no está reseñado en el cuadro que podría corresponder quizás con otros colectivos latinoamericanos.

Es evidente, como pasa en toda tabla de contingencia cuando se calcula a 100 en columna, que el valor esté condicionado al peso o influencia de la presencia de los marginales Alteri correspondientes. Pero, esta condición conocida e inscrita en la lógica de las tablas de contingencia, no deja de suponer que donde mayor \% hay más asociación comparando los porcentajes en fila.

7 Es importante advertir, como se observa en el cuadro, que por ahora no se ha hecho la distinción para los Alteri entre el colectivo de NC25-55pNC y el colectivo NC25-55pNE, todos están como Alteri en una misma categoría. 
REDES- Revista hispana para el análisis de redes sociales

Vol.20,\#4, Junio 2011

http://revista-redes.rediris.es

Segunda posibilidad: valor relativizado con respecto al marginal (Tabla 3).

El porcentaje precedente del indicador se lleva a cabo sobre el $100 \%$ de cada columna, esto es sobre todos los colectivos Alteri para cada colectivo de Egos.

\begin{tabular}{|c|c|c|c|c|c|c|}
\hline & $\begin{array}{c}\text { NC+55 } \\
\text { pNC }\end{array}$ & $\begin{array}{c}\text { NC25- } \\
\mathbf{5 5 p N C}\end{array}$ & $\begin{array}{c}\text { NC25- } \\
\mathbf{5 5 p N E}\end{array}$ & NE+55 & Ecuador & Marruecos \\
\hline (\% en columna-- & $77,4 \%$ & $70,6 \%$ & $33,5 \%$ & $48,0 \%$ & $59,7 \%$ & $73,2 \%$ \\
\% en marginal= & $40,2 \%$ & $15,0 \%$ & $15,0 \%$ & $15,6 \%$ & $10,2 \%$ & $12,7 \%$ \\
Diferencia & $\mathbf{3 7 . 2} \%$ & $\mathbf{5 5 , 6 \%}$ & $\mathbf{1 8 , 5 \%}$ & $\mathbf{3 2 . 4} \%$ & $\mathbf{4 9 , 5} \%$ & $\mathbf{6 0 , 5 \%}$ \\
\hline
\end{tabular}

Tabla 3. Segunda posibilidad de Indicador de Cohesión.

Este indicador calcula la diferencia entre el indicador precedente del Ego y el valor del porcentaje correspondiente a los Alteri del mismo Ego en la fila de los Alteri que aparece en la última columna del Total (este columna representa la distribución sobre 100 de todos los Alteri para cada colectivo de Alteri); de esta manera se relativiza el valor al porcentaje de los Alteri para el colectivo en cuestión. El resultado mantiene las tendencias pero atenúa considerablemente las diferencias. La diferencia es particularmente llamativa en el colectivo de los NC+55pNC (ver Figura 1).

Segundo tipo de Indicador de la Cohesión social por residuos ajustados

Un segundo indicador es el de residuo ajustado. La referencia del valor 0 es el de la independencia entre los valores de dicha cada casilla, lo que supone que los valores se ajustan al \% existente en la población, es decir lo que es lo que le corresponde. Un valor superior a 0 y significativo (superior a 1,96 o inferior a $1,96)$ supone que se puede hablar de Cohesión social homofílica superior, del lado positivo, al que le correspondería en condiciones de independencia; y su ausencia, los negativos. En este caso podría haber más Vinculación o Integración. En el cuadro se señalan solamente los residuos cuyos colectivos Ego coinciden con los correspondientes de los colectivos Alteri; esto es la Cohesión social. Si la segunda versión del Indicador relativizaba los datos suprimiendo el marginal en filas, el residuo ajustado lo relativiza con respecto a filas y columnas, al ser independiente del número de Alteri sea en filas sea en columnas. Se trata pues de un indicador simétrico y por tanto más cercano a la idea de asociación tomando sólo los colectivos del Ego con su Alteri como referencia. En nuestra opinión es más pertinente que los dos precedentes (Tabla 4).

\begin{tabular}{|c|c|c|c|c|c|}
\hline NC+55pNC & $\begin{array}{c}\text { NC25- } \\
55 p N C\end{array}$ & $\begin{array}{c}\text { NC25- } \\
55 p N E\end{array}$ & NE+55 & Ecuador & $\begin{array}{c}\text { MarrueCohesión } \\
\text { social }\end{array}$ \\
\hline 38,9 & 32,6 & 26,8 & 42,7 & 83,5 & 93,2 \\
\hline
\end{tabular}

Tabla 4. Tercera posibilidad de Indicador de Cohesión 
REDES- Revista hispana para el análisis de redes sociales

Vol.20,\#4, Junio 2011

http://revista-redes.rediris.es

Los resultados mantienen la misma tendencia aunque algunos colectivos como $\mathrm{NE}+55$ y de ecuatorianos aumentan relativamente

Este indicador parece el más 'ajustado' ya que examina exclusivamente las asociaciones netas entre colectivos a pares, el de los Egos y el de sus Alteri correspondientes a los mismos contenidos que los Egos.

Los tres indicadores de la Cohesión social (CoS)

CoS1\% : : Porcentaje Alteri en ídem Ego correspondiente

CoS2\% : Porcentaje Alteri en ídem Ego relativizado en filas

Cos3 : Residuos ajustados Alteri en ídem Ego

Datos y representación de los indicadores de Cohesión

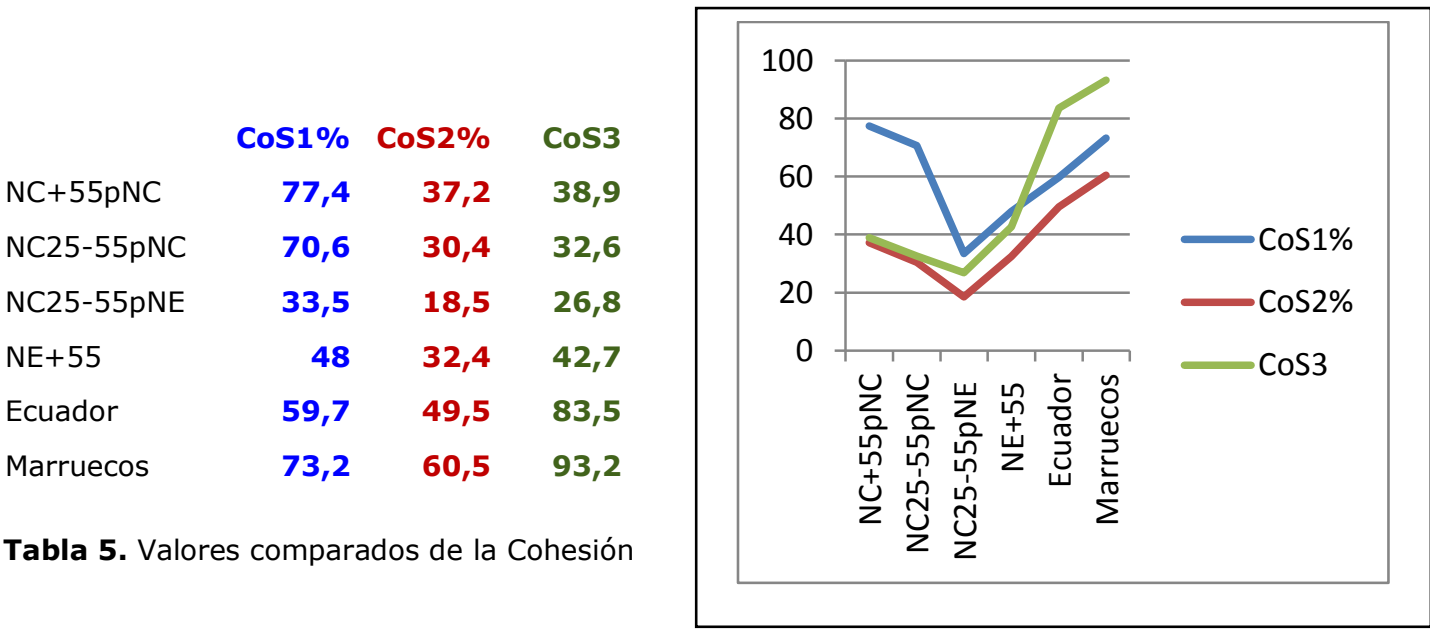

Figura 1. Valores comparados de la Cohesión

La tendencia de los tres indicadores es similar (Tabla 5, Figura 1) pero con diferencias entre, de un lado, CoS1\% y, del otro, CoS2\% y CoS3: el CoS1\% acentúa sobre todo la Cohesion social interna en los NC+55pNC y NC25-55pNC, debido a sus efectos marginales. El residuo ajustado expresa más adecuadamente, como afirma precedentemente, la relación recíproca de cada Ego con sus respectivos Alteri.

Los índices globales de la Cohesión homofílica.

Si se diera máxima Cohesión social en todos los colectivos sus valores serían máximos, en el caso, Chi2 $=32475$ y $\mathrm{Phi}=2,1$. Estos valores son prácticamente inalcanzables a no ser que se estuviera en situaciones completamente deterministas; además el Chi2 nos es lineal; los valores máximos sólo se alcanzan con una enorme asociación. Se muestran los tres indicadores globales. Hay pues 
REDES- Revista hispana para el análisis de redes sociales

Vol.20,\#4, Junio 2011

http://revista-redes.rediris.es

concentraciones remarcables en determinadas casillas y por tanto globalmente (Tabla 6).

\begin{tabular}{|c|c|c|c|}
\hline & Value & df & $\begin{array}{c}\text { Asymp. Sig. (2- } \\
\text { sided) }\end{array}$ \\
\hline Pearson Chi-Square & 19672,696 & 25 &, 000 \\
\hline Nominal by Nominal & Phi & 1,231 &, 000 \\
\cline { 2 - 4 } & Cramer's V &, 550 &, 000 \\
\hline
\end{tabular}

Tabla 6: Test de Chi cuadrado

Este indicador tiene el interés particular de dar una visión global de la Cohesión social y al mismo tiempo y relativamente también de la Integración social y Vinculación social según sean altos o bajos sus valores.

\subsection{Indicadores de la Vinculación social de naturaleza heterofílica}

Este indicador es más complicado definirlo pues no se trata de una distribución igualitaria entre todas las categorías de los Alteri (Integración máxima) ni de su concentración máxima en el grupo Alteri que coincide con su correspondiente grupo Ego (Cohesión máxima). Con todo, se puede afirmar que la Vinculación social no puede ser máxima cuando lo es la Cohesión social o la Integración social. Veamos dos indicadores posibles.

\section{Primer tipo de Indicador de Vinculación social}

El primer indicador es simple, se trata del número de casillas de colectivos Alteri, en columna del colectivo de Egos estudiado, exceptuando la casilla de Alteri del Egos analizados, que tienen un valor en porcentaje del colectivos de Alteri superior a la media de los porcentajes en la columna del Ego. Dicho valor medio está dado por $(100 \%) /\left(n^{\circ}\right.$ de columnas): $100 / 6=16,6$

Primer indicador de Vinculación social (1)

NC+55pNC : :0 colectivos de Alteri superan el 16,6

NC25-55pNC :1 colectivo de Alteri supera la media pero sólo con valor de 16,7

NC25-55pNE :2 valores que superan la media, CPnC con 39,4 y CnE con 22,5

E+55 :2 valores que superan la media, CPnC con 28,1 y CPnE con 21,4

Ecuador $\quad: 1$ valor que supera la media, Otros con 19,5

Marruecosl : :0 colectivo de Alteri superan el 16,6

De nuevo los mismos colectivos, NC25-55pNE y E+55 tiene vínculos especiales con colectivos de Alteri que no coinciden con los Egos estudiados. 
REDES- Revista hispana para el análisis de redes sociales

Vol.20,\#4, Junio 2011

http://revista-redes.rediris.es

Segundo tipo de Indicador de Vinculación social.

El segundo indicador consiste en la suma de la diferencia de cada porcentaje de las casillas con valores superiores al porcentaje medio precedente (esta media es $100 \%$ / número de columnas) menos el valor del porcentaje medio, todo ello dividido por (100-100/n) que sería el valor máximo que alcanzase el numerador.

$\begin{array}{lll}\text { NC+55pNC } & : \text { ningún valor supera la media } & =0,00 \\ \text { NC25-55pNC } & :(16,7-16,6) /(100-16,6) & =0,01 \\ \text { NC25-55pNE } & :(39,4+22,5-16,6 \times 2) /(100-16,6) & =0,34 \\ \text { E+55 } & :(28,1+21,4-16,6 \times 2) /(100-16,6) & =0,20 \\ \text { Ecuador } & :(19,5-16,6) /(100-16,69) & =0,02 \\ \text { Marruecos } & : \text { ningún valor supera la media } & =0,00\end{array}$

Los indicadores aparecen en la Tabla 7 y Figura 2. Los valores expresan la misa tendencia pero el segundo es más preciso. Los colectivos E+55 NC25-55pNE aparecen los más vinculantes y/o vinculados.

\section{Datos y representación de los indicadores de Vinculación}

$\begin{array}{lrr} & \text { VnS1 } & \text { VnS2 } \\ \text { NC+55pNC } & \mathbf{0} & \mathbf{0 , 0 0} \\ \text { NC25-55pNC } & \mathbf{1} & \mathbf{0 , 0 1} \\ \text { NC25-55pNE } & \mathbf{2} & \mathbf{0 , 3 4} \\ \text { NE+55 } & \mathbf{2} & \mathbf{0 , 2 0} \\ \text { Ecuador } & \mathbf{1} & \mathbf{0 , 0 2} \\ \text { Marruecos } & \mathbf{0} & \mathbf{0 , 0 0}\end{array}$

Tabla 7. Valores comparados de Vinculación.

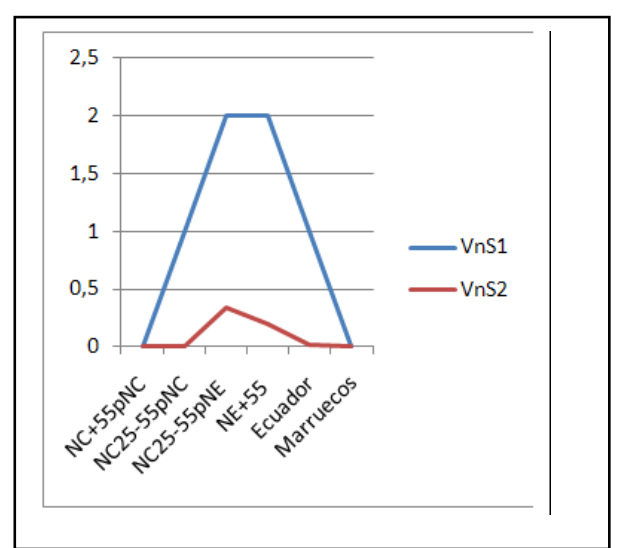

Figura 2. Valores comparados de la Vinculación.

\subsection{Indicadores de la Integración social de naturaleza heterofílica}

La Integración social se refiere a las relaciones, Linking. En el caso, (ver Lozares, Verd, López-Roldán, Martí, Molina, Bolibar y Cruz, 2011) consideramos tres tipos: el primero, tomando considerando el colectivo del Ego analizado con respecto a todos los colectivos de su columna; el segundo, ídem pero sólo con respecto a los que son superiores por alguna razón definida previamente como prestigio o poder; y un tercer tipo, similar con respecto a su acceso o pertenencia a instituciones u organizaciones, que es el contemplado en este artículo. 
REDES- Revista hispana para el análisis de redes sociales

Vol.20,\#4, Junio 2011

http://revista-redes.rediris.es

El primer tipo de indicadores de Integración social heterofílica.

Este tipo de Integración social de naturaleza heterofílica de un colectivo de Egos tiene como referencia la totalidad de los colectivos exceptuando el colectivo de Alteri que coinciden con el del Ego del que se analiza su Integración social. Son relaciones externas, inter o entre pero verticales al tomar como referencia la totalidad. Veamos dos componentes de este indicador, que han de ser dados de coordinadamente.

(1) El primer componente o condición necesaria pero no suficiente para la existencia de Integración social

Se calcula examinando los porcentajes en columna de los colectivos Alteri diferentes al del colectivo Ego que se analiza. Se trata pues de lazos o relaciones externos, esto es, con Alteri que no pertenecen al colectivo Ego. Si dichos porcentajes son iguales para un colectivo de Egos, se trata de una distribución equitativa de sus relaciones entre sus Alteri. Para cada colectivo Ego, columna (j), la fórmula se aplica pues a todas las filas (i) de colectivos Alteri para dicha columna ( $\mathrm{j}$ ), sin tener en cuenta $\mathrm{i}=\mathrm{j}$. Este indicador (1) de condición de igualdad en la Integración lo 'robamos' de la medición de la centralidad de grado de una Red aunque conceptualmente no tiene nada que ver.

(1) InS (j) : $\sum_{i=1}^{I}\left(\max X \%_{\max , j}-X \%_{i j}\right) / \mathrm{n}^{\circ} \mathrm{d}$ de filas

$i=$ filas, $j=$ comunas, tal que $i \neq j$

Que $i \neq j$ es porque no se considera el colectivo de Alteri que coincide con el mismo colectivo de Egos. La Integración social es máxima si el valor de este indicador es $0 \%$ pues indica que hay menos diferencias en las relaciones entre las de un colectivo de Egos con los diferentes colectivos de sus Alteri; mínima si el indicador es $100 \%$. Puesto que es lineal se puede hablar de una graduación de la Integración social.

Ejemplo:

$N C+55 p N C \quad:[(11,7-11,7)+(11,7-9,2)+(11,7-1,6)+(11,7-0)+(11,7-0)] / 5=44,5 / 5=8,8$

\section{Integración social InS1}

$\begin{array}{lll}\text { NC+55pNC } & : 44,5 / 5 & =8,8 \\ \text { NC25-55pNC } & : 54,1 / 5 & =10,8 \\ \text { NC25-55pNE } & : 130,5 / 5 & =26,1 \\ \text { NE+55 } & : 68,5 / 5 & =13,5 \\ \text { Ecuador } & : 57,2 / 5 & =11,4 \\ \text { Marruecos } & : 25,0 / 5 & =5,0\end{array}$


Como se aprecia este Indicador no da muestras de que los colectivos sean igualitarios.

(2) El segundo componente

Este componente ha de conjugarse con el primero de igualdad. Consiste en el valor de la distribución directa de los porcentajes para todos los colectivos Alteri diferentes a los del Ego que se analiza.

Puede darse el supuesto de que el $100 \%$ de la distribución se concentre en el colectivo de Alteri que corresponde al Ego, (es decir máxima Cohesión social); entonces la Integración sería 0 y por tanto igualitaria para todos los Alteri del Ego. Por tanto el Indicador (1), anterior de Integración social hay que sopesarlo con el que definimos como Indicador (2) porque es cuestión de que además de igualitaria sea lo máxima posible. El Indicador (2) expresa los valores medios del conjunto de los porcentajes de las relaciones de todos los colectivos para cada colectivo de Egos, sin contar el porcentaje que corresponde al mismo Ego. Si es máximo habrá máxima Integración social.

$$
\begin{aligned}
& \text { (2) InS (j) }: \sum_{i=1}^{I}\left(X \%_{i j}\right) / \mathrm{n} \circ \text { de filas } \\
& \mathrm{i}=\text { filas, } \mathrm{j}=\text { comunas, tal que } \mathrm{i} \neq \mathrm{j}
\end{aligned}
$$

\section{Integración social InS2}

$\begin{array}{lll}\text { NC+55pNC } & : 23,5 / 5 & =4,7 \\ \text { NC25-55pNC } & : 29,4 / 5 & =5,9 \\ \text { NC25-55pNE } & : 66,5 / 5 & =13,5 \\ \text { NE+55 } & : 58,5 / 5 & =11,6 \\ \text { Ecuador } & : 30,3 / 5 & =5,0 \\ \text { Marruecos } & : 26,5 / 5 & =5,5\end{array}$

Como se aprecia los grados de Integración son desiguales en los diferentes colectivos. La distribución de la equivalencia de distribución propia al Indicador (1) sigue casi la misma distribución que este Indicador (2): a mayor Integración, Indicador (2), menos equitativa su distribución, Indicador (1).

El segundo tipo de Integración social o de vínculos Linking

Este indicador tiene como referencia, para medir la Integración social de un colectivo de Egos, el porcentaje de los Alteri correspondiente, pero sólo de los que son 'superiores' al de dicho Ego. Lo de 'superiores' puede suponerse o entenderse con respecto a diferentes contenidos sociales como por ejemplo, jerarquía social, 
REDES- Revista hispana para el análisis de redes sociales

Vol.20,\#4, Junio 2011

http://revista-redes.rediris.es

desigualdad, poder, estudios, prestigio; si la diferencia no fuera pertinente socialmente no tiene sentido este indicador.

En el caso que nos ocupa, el criterio de desigualdad de jerarquía, poder o prestigio, puede inferirse del hecho de que una mayor Integración social o presencia (incluso de generaciones) mayor en una sociedad asegura mayor Capital social o de otros recursos como por ejemplo la lengua o lenguas oficiales o más compartidas, amén de otros signos de poder y prestigio que lo acompañan (dinero, nivel educativo u otros). Así puede establecerse un principio de jerarquía entre los colectivos estudiados. Por ello para la construcción de este indicador se recurre a atribuir a cada colectivo una ponderación; en este caso se ha recurrido al más natural suponiendo, muy elementalmente, una diferencia de 1 entre los colectivos. Esta ponderación se ha de refinar introduciendo coeficientes que tengan en cuenta las relaciones que guardan dichos colectivos con otras variables que manifiestan más claramente la jerarquía social como por ejemplo, CSP, nivel de estudios, ocupación, etcétera.

El indicador se construye a partir de las relaciones que mantiene un determinado colectivo con todos los que se encuentran en un nivel superior con respecto al total de las relaciones con todos colectivos tomados en ambos casos ponderadamente de manera lineal; esto es, no se tiene en cuenta la propia cohesión interna en el numerador ni en el denominador.

$$
\text { Segundo tipo de Ins (j) : } \frac{\sum_{i>j}^{I}\left(X \%_{i j}\right) \text { i. }}{\sum_{i>j}^{J} 100 i .}
$$

Integración (3) de los Egos(i) con valores ponderados, InS3

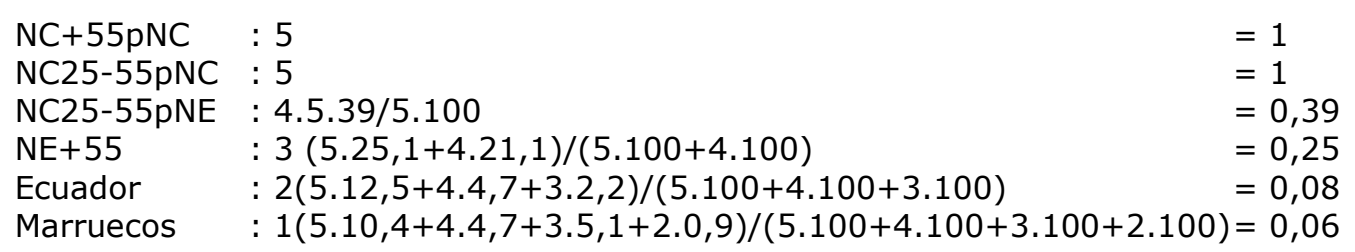

Como se ve el orden es decreciente según sea el tiempo de presencia (inserción o residencia) en la sociedad de recepción. Para el conjunto de las tres Integraciones ver Tabla 8, Figura 3. 
REDES- Revista hispana para el análisis de redes sociales

Vol.20,\#4, Junio 2011

http://revista-redes.rediris.es

Datos y representación de los indicadores de Integración.

$\begin{array}{lrrr} & \text { Ins1 } & \text { Ins2 } & \text { Ins3 } \\ \text { NC+55pNC } & \mathbf{8 , 8} & \mathbf{4 , 7} & \mathbf{1 , 0 0} \\ \text { NC25-55pNC } & \mathbf{1 0 , 8} & \mathbf{5 , 9} & \mathbf{1 , 0 0} \\ \text { NC25-55pNE } & \mathbf{2 6 , 1} & \mathbf{1 3 , 5} & \mathbf{0 , 3 9} \\ \text { NE+55 } & \mathbf{1 3 , 5} & \mathbf{1 1 , 6} & \mathbf{0 , 2 5} \\ \text { Ecuador } & \mathbf{1 1 , 4} & \mathbf{5 , 0} & \mathbf{0 , 0 8} \\ \text { Marruecos } & \mathbf{5 , 0} & \mathbf{5 , 5} & \mathbf{0 , 0 6}\end{array}$

Tabla 8. Valores comparados de la Integración.

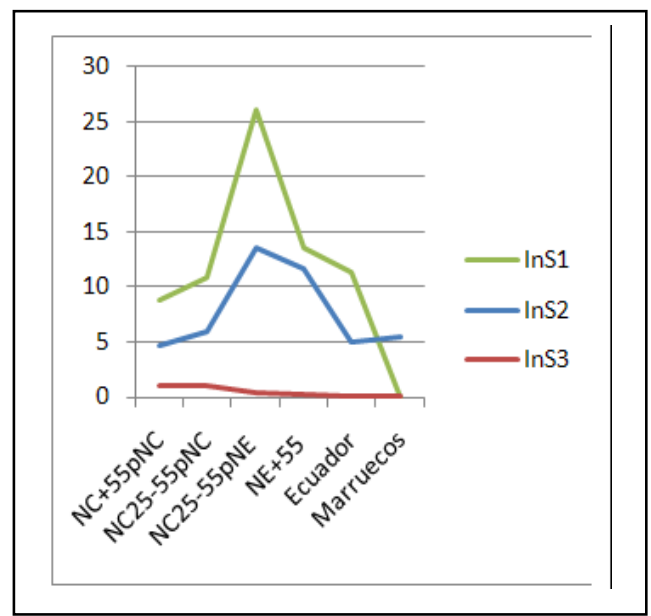

Figura 3. Valores comparados de la Integración

El tercer tipo de Integración social

Este indicador se refiere a las relaciones que mantienen los diferentes colectivos Egos con instituciones, ayuntamiento, escuela, organizaciones, asociaciones, servicios, etc. Todo ello directamente por los Egos o por mediación de sus Alteri. Este tipo de Integración social que es fundamental será objeto de tratamientos en posteriores análisis.

\subsection{EI reagrupamiento de colectivos Ego y de porcentajes de Alteri}

Para todos los colectivos Egos sus colectivos de Alteri pueden reagruparse según criterios que los puedan asimilar o componer. Ello simplifica, en brocha más gorda, el tratamiento pero perdiendo información. Se muestran dos tablas, que resaltan más los resultados, como muestra de posibilidades. No se hacen los cálculos de los indicadores pues serían más simples que en los casos precedentes (Tablas 9 y 10).

\begin{tabular}{|c|c|c|c|c|c|c|c|}
\hline \multirow{2}{*}{$\begin{array}{c}\text { Origen } \\
\text { Alteri }\end{array}$} & \multicolumn{6}{|c|}{ Origen Egos } & \multirow{3}{*}{$\begin{array}{c}\text { Total } \\
70,0 \%\end{array}$} \\
\hline & \multicolumn{4}{|c|}{$\mathrm{NC}+55 \mathrm{pNC} / \mathrm{NC2} 2-55 \mathrm{pNC} / \mathrm{NC25}-55 \mathrm{pNE} / \mathrm{NE}+55$} & \multicolumn{2}{|c|}{ Ecuador/Marruecos } & \\
\hline $\mathrm{CPnC}+\mathrm{CPnE}+\mathrm{CnE}$ & 98,4 & 95,2 & 95,4 & 97,6 & 19,4 & 20,0 & \\
\hline $\begin{array}{c}\text { Marruecos+ } \\
\text { Otro+ Ecuador }\end{array}$ & 1,6 & 4.8 & 4,6 & 2,4 & 80,6 & 80,0 & $30 \%$ \\
\hline Total & 2190 & 2280 & 2220 & 1950 & 2160 & 2190 & 12990 \\
\hline$\%$ & $100,0 \%$ & $100,0 \%$ & $100,0 \%$ & $100,0 \%$ & $100,0 \%$ & $100,0 \%$ & $100,0 \%$ \\
\hline
\end{tabular}

Tabla 9. Porcentajes acumulados en columnas que provienen de la Tabla 1. 
REDES- Revista hispana para el análisis de redes sociales

Vol.20,\#4, Junio 2011

http://revista-redes.rediris.es

\begin{tabular}{|c|c|c|c|}
\hline \multirow{2}{*}{$\begin{array}{c}\text { Origen } \\
\text { Alteri }\end{array}$} & \multicolumn{2}{|c|}{ Origen Egos } & \multirow{2}{*}{ Total } \\
\cline { 2 - 4 } & $\begin{array}{c}\text { NC+55pNC+ NC25-55pNC+ } \\
\text { NC25-55pNE+ NE+55 }\end{array}$ & Ecuador+Marruecos & $70, \%$ \\
\hline CPnC+CPnE+CnE & $96,0 \%$ & 19,7 & $30 \%$ \\
\hline Marruecos+ Otro+ Ecuador & 4,0 & 80,3 & $30 \%$ \\
\hline
\end{tabular}

Tabla 10. Reagrupamiento en filas a partir de la Tabla 1.

Las conclusiones son evidentes reforzando las precedente y estableciendo la distinción neta entre catalanes y nueva inmigración como correspondientes diferencias entre aborígenes y nuevos venidos. Con todo no son simétricas.

\subsection{El equilibrio Cohesión social e Integración social}

Se trata de conjugar la medición de la Cohesión social y la Integración social por medio de indicadores que den un cierto balance entre ambas: equilibrio o se maximiza una a costa de la otra. Según cómo o para qué, las tres situaciones, máxima Cohesión social y mínima Integración social, la inversa o en equilibrio entre ambas, pudiera tener efectos productivos diferentes con relación al mismo Capital social u otras formas de capital. Posiblemente, aunque no es objeto de este artículo, la efectividad de dicho balance estará en función del bien o recurso alcanzable en dicha estructura social; lo que parece relativamente claro es que un cierto equilibrio puede ser la situación ideal. El indicador del balance se toma de los precedentes, concretamente de los más directos de Cohesión social e Integración social, si bien se pudiera afinar más. Veamos dos tipos de indicadores Primer tipo de Indicador del balance Integración y Cohesión. Balance 1, Bal1

Definimos el Balance 1, Bal1 como el cociente entre la Cohesión social (2) y la Integración social (2), (Tabla 11, Figura 4)

Datos y representación de los indicadores de Integración.

$\begin{array}{lrrr} & \text { Ins2 } & \text { Cos2 } & \text { Bal1 } \\ \text { NC+55pNC } & \mathbf{4 , 7} & \mathbf{3 7 , 2} & \mathbf{7 , 9} \\ \text { NC25-55pNC } & \mathbf{5 , 9} & \mathbf{3 0 , 4} & \mathbf{5 , 0} \\ \text { NC25-55pNE } & \mathbf{1 3 , 5} & \mathbf{1 8 , 5} & \mathbf{1 , 3} \\ \text { NE+55 } & \mathbf{1 1 , 6} & \mathbf{3 2 , 4} & \mathbf{2 , 8} \\ \text { Ecuador } & \mathbf{5 , 0} & \mathbf{4 9 , 5} & \mathbf{9 , 9} \\ \text { Marruecos } & \mathbf{5 , 5} & \mathbf{6 0 , 5} & \mathbf{1 1 , 0}\end{array}$

Tabla 11: Valores de InS2, CoS2 y Bal1

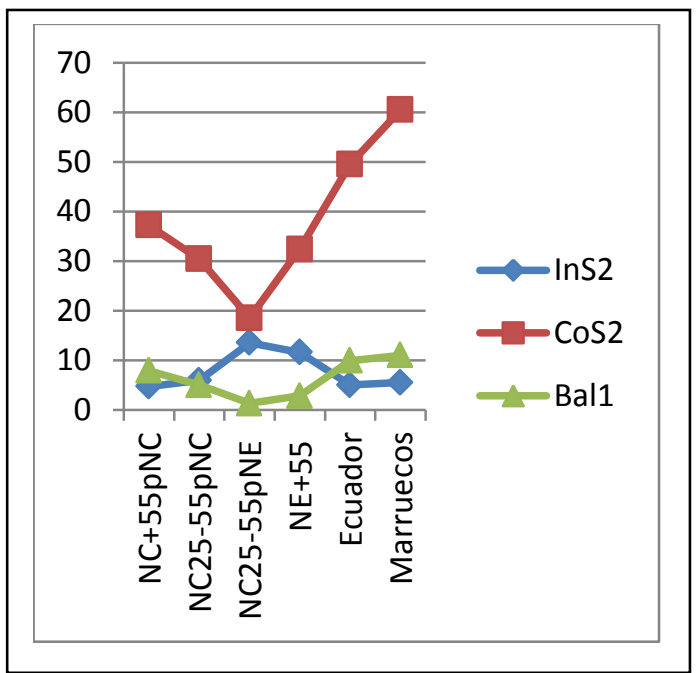


REDES- Revista hispana para el análisis de redes sociales

Vol.20,\#4, Junio 2011

http://revista-redes.rediris.es

Figura 4: Valores de InS2. CoS2 y Bal1

Claramente son los colectivos NC25-55pNE y NE+55 que más manifiestan un cierto equilibrio entre Cohesión e Integración, el resto tiende a hace predominar más las relaciones de Cohesión que de Integración.

Segundo tipo de Indicador del balance Integración y Cohesión. Balance 2, Bal2 Consiste en utilizar el mismo procedimiento que se ha propuesto para la Integración pero ahora teniendo en cuenta la Cohesión, esto es

Balance Integración $(\mathbf{j}): \sum_{i=1}^{I}\left(\max X \%_{\max . j}-X \%_{i j}\right) / \mathrm{n}$ o de filas $i=$ filas, $j=$ comunas,

Cuanto mayor sea el cociente más alejado se encuentra la Cohesión social y la Integración social de una distribución equitativa. El valor 0 significa que la distribución es igual en los porcentajes por columna, es el caso de Integración social perfecta. Veamos el cálculo y sentido del indicador, (Tabla 12, Figura 5)

Si un valor del porcentaje en columna fuera $100 \%$ y el resto 0 el cálculo sería $(100 \times 6-100) / 6=5.100 / 6=83,3$ sería el valor del máximo desequilibrio, es decir la ausencia de la mínima Integración social, lo que significa que sea de máxima Cohesión social. Sería el caso de máxima Cohesión social si el valor del $100 \%$ fuera de un valor del colectivo Alteri que coincidiera con el colectivo Ego analizado.

Observamos que la máxima Integración social con relación a una mínima Cohesión social sucede como estaba previsto en los, NC25-55pNE, E+55 y los mínimos de Integración social y en el caso máximos de Cohesión social los NC+55pNC,NC25-55pNC, Ecuador y Marruecos.

Datos y representación de los indicadores de Balances

$\begin{array}{llr} & \text { Bal2 } & \text { Bal1 } \\ \text { NC+55pNC } & :(37,2 \times 6-100) / 6=\mathbf{2 2 , 2} & \mathbf{7 , 9} \\ \text { NC25-55pNC } & :(30,4 \times 6-100) / 6=\mathbf{1 3}, \mathbf{7} & \mathbf{5 , 0} \\ \text { NC25-55pNE } & :(18,5 \times 6-100) / 6=\mathbf{1 , 8} & \mathbf{1 , 3} \\ \text { E+55 } & :(32,4 \times 6-100) / 6=\mathbf{1 5 , 7} & \mathbf{2 , 8} \\ \text { Ecuador } & :(49,5 \times 6-100) / 6=\mathbf{3 2 , 8} & \mathbf{9 , 9} \\ \text { Marruecos } & :(60,5 \times 6-100) / 6=\mathbf{4 3 , 8} & \mathbf{1 1 , 1}\end{array}$

Tabla 12: Valores de Bal 2 y Bal1

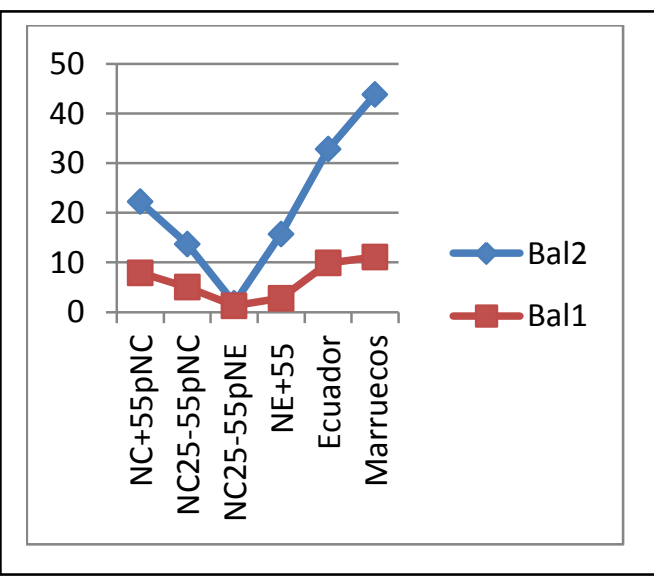


REDES- Revista hispana para el análisis de redes sociales

Vol.20,\#4, Junio 2011

http://revista-redes.rediris.es

Figura 5: Valores de Bal2 y Bal 1

Las tendencias son idénticas; El Bal2 es más preciso y diferenciado3. Entre los dos tipos de indicadores se observa una buena correspondencia.

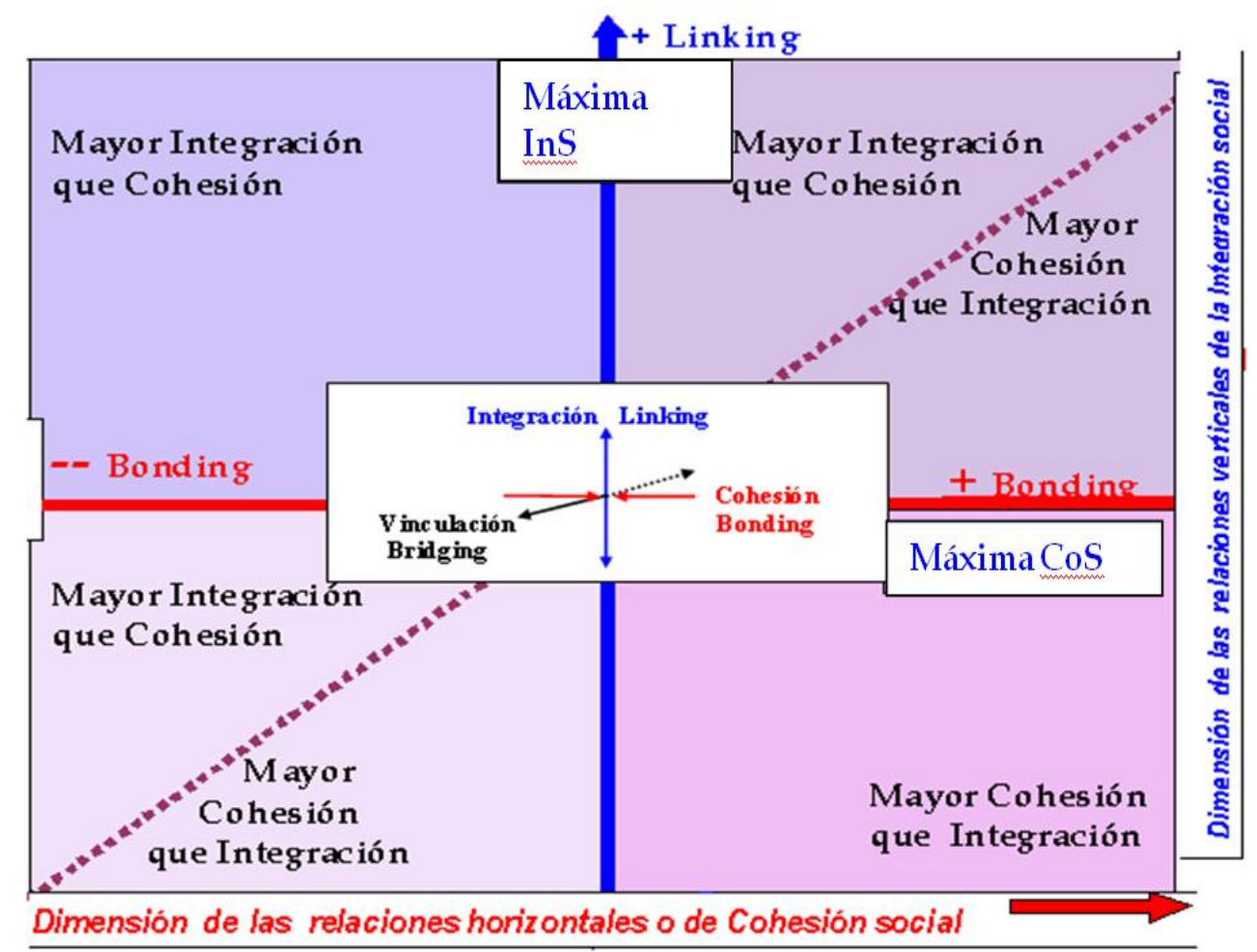

Figura 6. El balance entre Cohesión social y la Integración social

La Figura 6 representa en un plano, en dos dimensiones, el balance entre Cohesión social, boding, en el eje horizontal con máxima Cohesión social en la derecha hasta llegar a la fusión social y en el eje vertical la Integración social linking, con el máximo en la parte más elevada. En ambos casos se representa de forma lineal, es decir, que se toman los indicadores dados por porcentajes, tanto para la Cohesión social como para la Integración social; en particular para Integración social sólo se consideraría, en esta representación, el primer tipo de Integración social, el referido a las relaciones con todos los colectivos. El plano queda dividido en cuatro cuarterones que representan todas las posibilidades del balance entre la Cohesión y la Integración social. La línea diagonal establece, por encima, la zona de más valor en la Integración social que Cohesión social y por debajo la inversa. El cuadro pequeño central en blanco corresponde a la tercera dimensión al introducir la Vinculación social, bridging, que se representaría por un eje perpendicular al papel. 
REDES- Revista hispana para el análisis de redes sociales

Vol.20,\#4, Junio 2011

http://revista-redes.rediris.es

\section{Conclusiones}

Para este comentario final se ha de retornar al objetivo fundamental que se anunciaba. Se trata de mostrar las posibilidades de análisis que ofrecen las Egocentradas en lo que se refiere a la Cohesión, Vinculación e Integración social. Por ello el artículo indaga en ellas haciendo una serie de propuestas de operativización de dichos conceptos y de análisis a partir de un caso de aplicación. Pero no están todos los indicadores posibles pues solo se reducen, como un primer paso, a bivariados de tablas de contingencia; esto es, se dejan de lado los multivariados con estas variables de cariz cualitativo. Además no se consideran, y es un muy importante camino, el estudio por ejemplo de los parámetros de asociación entre categorías del log-lineal.

También se dejan de lado las otras dos posibilidades de que se anuncian al inicio. La primera, la que iría de los Bonding, Cohesión social, Bridging, Vinculación social y Linking, Vinculación social, de las redes sociométricas de los Alteri a los atributos (o caracterización) de los Egos; la segunda en el sentido opuesto, de los Egos tipologías de Egos por sus características o atributos, a su caracterización por las formas de Cohesión social, Vinculación social e Integración social que provienen de las relaciones sociométricas de sus Alteri. Pero todo será explorado.

Hemos querido avanzar los indicadores propuestos tratando de exprimir al máximo las posibilidades del método bivariado de tablas de contingencias pues tiene un carácter directo y descriptivo que facilita considerablemente la comprensión de otros métodos más sofisticados o incluso explicativos.

Otro de los objetivos perseguidos consiste en la comparabilidad de indicadores diversos para los mismos conceptos, guardando una cierta lógica paralela para el conjunto de los conceptos. En este sentido las semejanzas y la coherencia son notables.

\section{Bibliografía}

Adler, P.S.; Kwon, S.W. (2000). "Social Capital: The Good, the Bad, and the Ugly" en Lesser E.L., Knowledge and Social Capital. Woburn MA: ButterworthHeinemann, pp. 89-114.

Adler, P. S.; Kwon S.W. (2002). "Social Capital: Prospects for a New Concept", Academy of Management Review, no 27(1): 17-40.

Borgatti, S.; Jones C.; Everett M. (1998). "Network Measures of Social Capital", Connections, no 21 (2): 1-36.

Brehm, J.; Rahn W. (1997). "Individual-Level Evidence for the Causes and Consequences of Social Capital," American Journal of Political Science no 41:9991023 
REDES- Revista hispana para el análisis de redes sociales

Vol.20,\#4, Junio 2011

http://revista-redes.rediris.es

Burt, R.S. (1992). Structural Holes: The Social Structure of Competition, Cambridge, MA: Harvard University Press.

Burt, R.S. (1997). "The contingent value of social capital", Administrative Science Quarterly, no 42: 339-365.

Cheong, P.; Edwards, R.; Goulbourne, H.; Solomos, J. (2007). "Immigration, Social Cohesion and Social Capital: A Critical Review", Critical Social Policy, n 27: 24-49.

Granovetter, M. (1973). "The strength of weak ties", American Journal of Sociology, no 78: 1360-1380.

Granovetter, M. (1974). Getting a Job: a study of contacts and careers, Cambridge, Mass: Harvard University Press.

Knoke, D. (1999). "Organizational networks and corporate social capital" en Leenders R. Th.; Gabbay S.M. (eds.) Corporate social capital and liability, Boston: Kluwer, pp-17-20.

Lin, N. (1999). "Building a Network Theory of Social Capital", Connections, no 22(1): 28-51.

Lin, N. (2001). Social Capital: a theory of social structure and action. Cambridge: Cambridge University Press.

Lopez Roldán P.; Lozares C. (2008a). "Implicaciones sociológicas en la construcción de una muestra estratificada", Empiria, nº 14:87-108.

Lopez Roldán P.; Lozares C. (2008b). "La construcción de la muestra. El trabajo de campo de la Encuesta de condiciones de vida y hábitos de la población de Catalunya" Metodologies i Recerques. IERMB, Barcelona, no 1:17-39

Loury, G. (1992). "The economics of discrimination: Getting to the core of the problem", Harvard Journal for African American Public Policy. no 1(1): 91-110

Lozares, C. (1996). "La teoría de redes sociales", Papers, no 48.

Lozares, C. (2006). "Valores, Campos y Capitales sociales", Redes. Volumen especial, Bellaterra: Publicaciones UAB, pp. 51-89

Lozares, Carlos; Verd, Joan Miquel; López-Roldán, Pedro; Martí, Joel y José Luis Molina (2011) "Cohesión, Vinculación e Integración sociales como formas de Capital social", REDES-Revista hispana para el análisis de redes sociales, vol. 20 \#1 (http://revista-redes.rediris.es)

Lozares, Carlos y Verd, Joan Miquel. (2011) De la Homofilia a la Cohesión social y viceversa. REDES-Revista hispana para el análisis de redes sociales, vol. 20 \#2 (http://revista-redes.rediris.es)

Narayan, D. (1999). Bonds and Bridges: Social capital and poverty, Word Bank, Washington DC.

Szreter, S.; Woolcock M. (2004). "Health Social capital, social theory and the political economy of public health". Int J Epidemiol, no 33:650-667.

Verd, J.M.; Lozares C.; Martí J.; López P. (2000). "Aplicació de les xarxes socials a I'analisi de la formació invisible en I'empresa", Revista Catalana de Sociologia, no 11: $87-104$

Vranken, J. (2001). "No Social Cohesion without Social Exclusion?" Research Unit on Poverty, Social Exclusion and the City, University of Antwerp, at http://www.shakti.uniurb.it/eurex/syllabus/lecture4/Eurex4-Vranken.pdf 
REDES- Revista hispana para el análisis de redes sociales

Vol.20,\#4, Junio 2011

http://revista-redes.rediris.es

Woolcock, M. (2003). "Diversity as opportunity and challenge: the role of social capital theory, evidence and policy", presentation to the Policy Research Initiative Conference, Montreal.

Woolcock, M.; Narayan, D. (2000). "Social Capital: Implications for Development Theory", Research, and Policy, The World Bank Research Observer, no 15(2): 22549.

\section{ANEXO 1. PREgUNTAS A CADA Ego SOBRE Sí MISMO/A.}

1. Lugar de residencia

2. Edad

3. Nacionalidad española

4. Nacimiento y origen

5. Género

6. Años de residencia en Catalunya

7. Situación familiar

8. Número de hijos

9. Número de personas que viven en su casa

10. Características de las personas con las que conviven con el Ego

11. Lengua de origen: ¿Cuál es su lengua de origen familiar o materna?

12. Lengua de uso habitual: ¿Qué lengua usa habitualmente en familia?

13. Lengua de uso habitual: ¿Qué lengua usa habitualmente en el trabajo?

14. Lengua de uso habitual: ¿Qué lengua usa habitualmente en la vida social, ocio, amigos?

15. Nivel de estudios acabados

16. Situación laboral actual

17. Situación laboral hace dos años

18. Profesión u ocupación actual o última

19. Categoría socio-profesional actual (o tenía en caso de ya no sea activo)

20 Religión

21. Para religión protestante (respuesta 3 en 20)

22. Para otras religiones (respuesta 4 en 20)

Pertenencia asociaciones, grupos

Pertenencia Dirigente Activo No activo

23 Religioso 24

25 Ocio, deportivo 26

27 Cultural $\quad 28$

29 Político 30

31 Social, sindical, $\quad 32$

33 Profesional 34

35 Educativa, padres 36

37 Inmigración 38 
REDES- Revista hispana para el análisis de redes sociales

Vol.20,\#4, Junio 2011

http://revista-redes.rediris.es

39 Otras 40 ¿Cuál? 41

Relaciones con Integración socialtituciones

42 .. a cursos de idiomas

43 .. a cursos formación para el trabajo?

44 .. a las oficinas de empleo?

45 .. a centros asistenciales?

46 ¿Ha hablado regularmente con profesores de su hijo en su etapa educativa?

47 Permiso de residencia?

\section{ANEXO 2. PEgUNTAS A Ego PARA genERAR LOS ALTERI Y LAS RELACIONES MUTUAS}

\section{Pregunta al Ego para generar sus Alteri.}

\section{Generador de nombres}

Por favor, escriba una lista de 30 personas que Usted conozca por su nombre y viceversa con las que ha tenido contacto al menos en los dos últimos años por cualquier medio de comunicación y que además pueda volver a contactarla si fuese necesario. No incluya personas menores de 18 años.

Puede ser cualquier persona. Intente incluir gente que sea próxima e importante para Usted. Luego puede incluir personas que no siendo tan cercanas aCohesión social tumbra a ver mucho. Luego puede extender su memoria a otras personas. Puede ayudarle pensar en diferentes grupos de personas en diferentes lugares, familia, amigos, compañeros, vecinos,.. Ponga el nombre y el apellido de forma abreviada para que solamente Usted pueda reconocer a las personas. Es importante que no abrevie demasiado para poder reconocerlas más tarde. Por ejemplo: Mig Cervan por "Miguel de Cervantes".

(Nombre en el cuadro de la página siguiente en la primera columna).

\section{Pregunta al Ego para generar la matriz de la red sociométrica entre sus Alteri}

"Por último le vamos a pedir que nos diga si cada una de las personas que ha nombrado (los Alters) tiene o relación con el resto y con quiénes. El contenido de dicha relación ha de ser de la misma naturaleza que la que ha empleado Vd para nombrarlo, es decir ¿quién conoce a quién?, entendiendo por conocer que se conocen por su nombre, ha tenido algún tipo de contacto en los dos últimos años por cualquier medio de comunicación y pueden volver a contactarse por cualquier razón" (Tabla 8)

B.1. Generador de Nombre o símbolo persona de la lista
C.1. Relaciones entre los alteri

Número de cada alter que mantiene relación con cada alter de la primera columna 
REDES- Revista hispana para el análisis de redes sociales

Vol.20,\#4, Junio 2011

http://revista-redes.rediris.es

\begin{tabular}{|l|l|}
\hline 1 & \\
\hline 2 & \\
\hline 3 & \\
\hline 4 & \\
\hline 5 & \\
\hline 6 & \\
\hline$\cdots$ & \\
\hline$\cdots$ & \\
\hline 30 & \\
\hline
\end{tabular}

Tabla 8. Los Alteri y relaciones entre Alteri

ANEXO 3. PREgUNTAS A EgO PARA CARACTERIZAR A CADA UNO DE SUS ALTERI.

1. Ciudad y país de residencia actual del Alter

2. Si otra ¿Cuál?

3. Años de residencia en Catalunya del Alter

4. Origen del Alter

5. Otras

6. Permiso de residencia del Alter

7. Edad del Alter

8. Género del Alter

9. Tiempo de conocimiento o relación

10. Lugar del Ego en el que se inició la relación

11. En caso de respuesta 3. ¿Cuál

12. Lugar del Alter en el que se inició la relación

13. En caso de respuesta 3. ¿Cuál.

14. Nivel de estudios acabados del Alter

15. Situación laboral actual

16. Categoría socio-profesional actual (o tenía en caso de ya no sea activo)

Otras características del Alter

17. Familia o núcleo familiar

18 Nivel de amistad del Ego con relación a los Alteri:

19. Pertenencia del Alteri a la misma Profesión que el Ego:

20. Pertenencia del Alteri a la misma Empresa u organización que el Ego:

21. Pertenencia del Alteri a la misma Asociación que el Ego:

22. Pertenencia del Alteri al misma Vecindario o barrio que el Ego:

23. Acuden o han acudido los hijos del Alteri al mismo colegio que los del Ego?

24. Pertenencia del Alteri a la misma Confesión religiosa que el Ego

Acceso del Alteri a las Integración socialtituciones 
REDES- Revista hispana para el análisis de redes sociales

Vol.20,\#4, Junio 2011

http://revista-redes.rediris.es

¿Esta persona o Alter le ha proporcionado a Vd (o Vd a ella), sea en la actualidad o en el pasado, informaciones útiles u otros medios o ayudas para encontrar o solucionar cuestión de e,

25. Trabajo

26. Vivienda

27. Salud, médiCohesión social, hospital, servicios de salud

28. Escuela para hijos, otros familiares

29. Servicios sociales y administrativos

30. Problemas personales

¿Esta persona o Alter le ha proporcionado (o Ud. a ella), sea en la actualidad o en el pasado ayuda para superar otras situaciones no mencionadas anteriormente

31. Otros ámbitos 